\title{
Parametric Survival Models of Hemodialysis Patients in Relation with Patient-Related Factors
}

Reem Yousif MEKKI ${ }^{1,2}$, Mohamed Hassan MUDAWI ${ }^{4}$, Manahil Saidahmed MUSTAFA', Altaiyb Omer Ahmed MOHMMED' , Ahmed Bakheet Abd ALLA³, Abdel Rahman AHMED ${ }^{5}$

\begin{abstract}
Background: Survival analysis refers to analyzing of statistical data for which the outcome variable of interest is time until an event occurs. This research aimed at comparing different models of parametric Proportional Hazards (PH) models (Weibull, exponential, Gompertz) in patients with hemodialysis to determine the best model for assessing the survival of patient. Study consists of 325 hemodialysis patients who referred to public hospitals in Khartoum state in the period from December 2005 to December 2015. Data was used to estimate the survival function with view to identify risk factors influencing among end-stage renal disease (ESRD) population. Based on the Cox-Snell Residuals and $\mathrm{AIC}, \mathrm{BIC}$, and Gompertz $(\mathrm{PH})$ model is an efficient model than other when the values of $(A I C=662.21),(B I C=703.83)$ and $(R 2=0.211)$ where maintained Study assessed that the variables dealing with univariate models were significant but had a significant effect on hemodialysis survival. The Gompertz model had the smallest AIC and BIC value; therefore; it was selected as the most appropriate model. In multivariable analysis, the BIC had the lowest value and the highest value in each analysis. The study assessed that diabetes mellitus and hypertension, regular, and hospital, had a. significant effect.
\end{abstract}

Keywords: survival analysis, parametric models, hemodialysis, Cox-Snell residuals, AIC, BIC, R2.

\section{INTRODUCTION}

Survival analysis focuses on estimating the probability about individual who will hazard for a given length of time until death. Survival analysis is particularly useful when the probability of occurrence of the event under study changes with time ${ }^{1-3}$.

The final stage of chronic kidney disease is End-stage Renal Disease (ESRD) and is characterized by pro- gressive permanent kidney failure. Dialysis therapy is a procedure aimed at eliminating the body's excrement and toxic substances and compensating for the loss of function of the kidneys. One dialysis class is hemodialysis ${ }^{4}$. It has been estimated that more than 1.1 million patients worldwide are estimated to have ESRD, with an addition of 7 percent annually. For example, incidence and prevalence levels in the United States are projected to increase by $44 \%$ and $85 \%$, respectively,

\footnotetext{
${ }^{1}$ College of Science, Sudan University of Science and Technology

${ }^{2}$ College of Computer Science and Mathematics, University of Bahri, Sudan

${ }^{3}$ College of Medical Laboratory Science, Sudan University of Science and Technology

${ }^{4}$ College of Social and Economic Studies, University of Bahri, Sudan

${ }^{5}$ College of Petroleum Geology and Minerals, University of Bahri,

Sudan
}

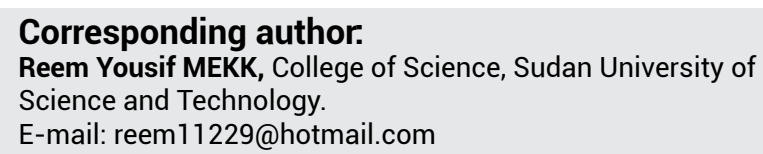

Corresponding author.

E-mail: reem11229@hotmail.com 
from 2000 to 2015, and incidence and prevalence rates per million population by $32 \%$ and $70 \%$. The progress of ESRD patients in developing countries has similar trends $s^{5}$.

Sudan is one of the countries where the chronic kidney failure is alarming. The frequency reported rate of (ESRD) new cases in Sudan is 70-140 per million people annually. The data available about the root a cause of rental disease that leads to chronic rental disease is very limited ${ }^{5,6}$.

Scientific studies have uncovered major causes of end stage renal disease in survival time. These causes are affecting in the survival of hemodialysis patients for a live long time. Millions of people are being affected with outbreak of kidney disease around the world.

This study is to compare the performance of different parametric models of the survival of hemodialysis patients. Parametric models were selected to estimate the survival probabilities. The application of these models helps to identify the prognostic factors that resulted in increasing the probability of survival.

\section{MATERIALS AND METHODS}

This study consisted of 325 hemodialysis patients who referred to public hospitals named Ahmed Gasim, Ibn Sina, Omdurman, Selma center, Bahri, and Ribat in Khartoum State during the period of time (December 2005 to December 2010) and then they were followedup till 2015. Data captured age, date of diagnosis of the disease, survival status even in the case of death or alive per months, sex, marital status, education level and occupation.

\section{DATA COLLECTION}

Khartoum State composed of 3 biggest cities named Khartoum, Bahri and Omdurman. Data of the study were collected from the biggest and well-known public hospitals in these three cities. Total number of patients covered in our study was 325 .

\section{INCLUSION CRITERIA}

In the period from December 2005 to December 2015, all hemodialysis patients referred to the 6 public hospitals were included and all age ranges were included.

\section{EXCLUSION CRITERIA}

Patients with hemodialysis that have been diagnosed with acute renal failure, inadequate medical history, pa- tients with hemodialysis who have stayed for a brief period of time and those in emergency conditions have been removed.

\section{DATA ANALYSIS}

The descriptive statistical analysis, percentage, and frequency were measured using Microsoft Excel software. In addition to the variables considered in this analysis, qualitative variables like (sex, marital status , education, occupation, daily dialysis, weekly frequency dialysis, hospital, diabetes mellitus and hypertension, diabetes mellitus, polycystic kidney disease, renal obstructions, shrunken kidney, unknown and other) and quantitative variables were classified into effective variables.

The log-rank test is a statistical test used to compare the survival distributions of two or more groups used to test the hypothesis where there is no difference between the categories for and variable. It does not provide any estimation of the actual size of the effect; in other words, it provides a statistical, but not a clinical, assessment of the effect of the factor.

In this analysis, the quantitative variables were not distributed as usually calculated by the KolmogorovSmirnov test when the probability value was higher than the significance level of 0.05 , so the parametric method was used.

The form of Survival Analysis has been applied in this study was heavily relied on both a Univariate where there is only one explanatory variable required and Multivariate where at least two explanatory variables 7 of patients with chronic kidney disease diagnosed with ESRD under hemodialysis care as they explained in Tables 5 and 6.

\section{Parametric models}

A parametric survival model time is supposed to follow a certain distribution, which its probability density function can be represented by unknown parameters. Weibull, Exponential, Gompertz, log logistic, lognormal and gamma distributions are widely used ${ }^{1,8,9}$.

\section{Parametric proportional hazard ( $\mathrm{PH}$ ) Models}

Cox (1972) introduced the parametric (PH) model it's also known as the Cox regression model. The widely used models are Exponential, Weibull and Gompertz distribution ${ }^{2,10,11}$. 


\section{Exponential Distribution}

The simplest and most important distribution in survival studies is the exponential distribution. It is often referred to as a purely random failure pattern.

The hazard function is

$$
h(t)=\lambda, \quad t \geq 0
$$

A constant, independent of $t$.

The corresponding survivorship function is

$$
S(t)=e^{-\lambda t} \quad \mathrm{t} \geq 0
$$

and so the implied The probability density function Survivorship function is

$$
f(t)=\lambda e^{-\lambda t} \quad t \geq 0, \quad \lambda>0
$$

A high $\lambda$ value shows high risk and limited survival; a low $\lambda$ value shows low risk and long survival. The distribution is also referred to as the unit exponential when $\lambda=1^{2,3,11}$.

Under the exponential PH model, the hazard function of a particular patient with covariates $x_{1}, x_{2}, x_{3} \ldots$ $x_{p}$ is given by

$$
\mathrm{h}(\mathrm{t} \mid \mathrm{x})=\lambda \exp \left(\mathrm{B}_{1} \mathrm{x}_{1}+\mathrm{B}_{2} \mathrm{x}_{2}+\mathrm{B}_{3} \mathrm{x}_{3}+\cdots+\mathrm{B}_{\mathrm{P}} \mathrm{X}_{\mathrm{P}}\right)=\lambda \exp (\dot{\mathrm{B}} \mathrm{x})
$$

\section{Weibull Distribution}

Proposed by Weibull (1939) and its applicability to different cases of failure, again discussed by Weibull (1951). In several studies of reliability and mortality from human diseases, it was then used ${ }^{2,3,11}$.

$$
h(t)=\lambda \gamma t^{\gamma-1},
$$

Amore general form of hazard function is such that

The survivor function is

$$
S(t)=\left\{-\int_{0}^{t} \lambda \gamma u^{\gamma-1} d u\right\}=\exp \left(-\lambda t^{\gamma}\right)
$$

The corresponding probability density function is then

$$
f(t)=\lambda \gamma t^{\gamma-1} \exp \left(-\lambda t^{\gamma}\right)
$$

The shape and scale parameters are therefore called gamma and $\lambda$, under the Weibull PH model, the hazard function of a specific patient is provided by the hazard function of a specific patient.

$$
\mathrm{h}(\mathrm{t} \mid \mathrm{x})=\lambda \gamma \mathrm{t}^{-1} \exp \left(\mathrm{B}_{1} \mathrm{x}_{1}+\mathrm{B}_{2} \mathrm{x}_{2}+\mathrm{B}_{3} \mathrm{x}_{3}+\cdots+\mathrm{B}_{\mathrm{P}} \mathrm{X}_{\mathrm{P}}\right)=\lambda \gamma \mathrm{t}^{\gamma-1} \exp (\hat{\mathrm{B} x})
$$

\section{Gompertz Distribution}

The Gompertz model has found application in demography and the biological sciences. In the particular case where $\gamma=0$, the hazard function has a constant value. The hazard function increases with time, decreases with time ${ }^{2,11}$.

$$
h(t)=\exp (\lambda+\gamma t)
$$

This shows that linear int. is the log-hazard function. Monotonically, the Gompertz risk increases or decreases. The survival function is

$$
S(t)=\exp \left[-\frac{e^{\lambda}}{\gamma}\left(e^{\gamma t}-1\right)\right],
$$

And the corresponding density function is

$$
f(t)=\exp \left[(\lambda+\gamma t)-\frac{1}{\gamma}\left(e^{\lambda+\gamma t-} e^{\lambda}\right)\right],
$$

Under the Gompertz PH model, the hazard function of a particular patient is given by

$\mathrm{h}(\mathrm{t} \mid \mathrm{x})=\lambda \exp (\gamma \mathrm{t}) \exp \left(\left(\mathrm{B}_{1} \mathrm{x}_{1}+\mathrm{B}_{2} \mathrm{x}_{2}+\mathrm{B}_{3} \mathrm{x}_{3}+\cdots+\mathrm{B}_{\mathrm{P}} \mathrm{x}_{\mathrm{P}}\right)\right)=\lambda \exp (\dot{\mathrm{B} x}) \exp (\gamma \mathrm{t})$

\section{Selection Criterion}

One of these criteria is the information criterion of Akaike (AIC), the Baysian Information Criterion (BIC) and the Cox-Snell Information Criterion (CSIC), the latter of which is a graphic rather than a mathematical criterion, many of the criteria used to choose the best model from different models deal with the same data for prediction in the future.

AIC: Comparisons may also be made on the basis of statistics between a variety of potential models which do not necessarily need to be nested ${ }^{2,12-14}$. 


$$
\text { AIC }=-2(\log \text { likelihood })+2(\mathrm{P}+\mathrm{K})
$$

Where $\mathrm{P}$ is the number of parameters, and $\mathrm{K}$ is the number of (excluding constant) coefficients in the model. For $\mathrm{P}=1$, for $\mathrm{P}=2$, for Weibull and Gompertz, for the exponential. The smaller the value of this statistic, the better the model, the better this statistic is known as Akaike's knowledge criterion.

BIC: The Baysian Information Criteria (BIC) is given by $^{15,16}$.

$$
B I C=-2(\log \text { likelihood })+(P+K) * \log (n)
$$

In the distribution, where $\mathrm{P}$ is the number of parameters, $K$ is the number of coefficients and $n$ is the number of observations. As the best-fit model, the distribution that has the lowest $\mathrm{BIC}$ value is considered a metric to test the goodness-of - fit of a regression model for proportional hazards. As a descriptive statistics for goodness of fit, Hosmer and Lemeshow propose the following ${ }^{17,18}$.

$$
R_{\mathrm{p}}^{2}=1-\left\{\exp \left[\frac{2}{\mathrm{n}}\left(\mathrm{L}_{0}-\mathrm{L}_{\mathrm{p}}\right)\right]\right\}
$$

Where the log likelihood for the fitted model with $\mathrm{p}$ covariates is LP, and L 0 is the log likelihood for model zero, the model without covariates is the log probability.

Cox Snell-Residual: The Cox-Snell Residuals can be used to check the quality of the model's fit ${ }^{15,19}$, defined as the person with observed time $t$

$$
r_{C i}=\widehat{H}_{i}\left(t_{i}\right)=-\log \hat{S}_{i}\left(t_{i}\right)
$$

Where $H_{i}\left(t_{i}\right)$ is estimated cumulative hazard function, and $S_{i}\left(t_{i}\right)$ is the estimated survivor function in equation are plotted against .

\section{Ethical Considerations}

The study protocol was authorised by the ethics and research committees of the Ministry of Health of Khartoum (serial number: KMOH-REC-1-2020). Hospitals received informed consent.

\section{RESULTS}

Our findings showed that a total of 325 patients with hemodialysis were enrolled in this study. The demographic characteristics of the targeted patients showed that $59.7 \%$ were male, $40.3 \%$, were female in terms of sex. By December 2015, $52.3 \%$ of patients had died and $47.7 \%$ were still alive, according to survival status. The marital status of the patients showed that $2.5 \%$ were divorced, $71.4 \%$ were married, $24 \%$ were single and $2.2 \%$ were widowed. Education revealed that 7.7 $\%$ of patients were illiterate, $32.6 \%$ received basic education, $4 \%$ were intermediate, $39.1 \%$ completed secondary education and $16 \%$ graduated. Patients' occupation wise shows that $18.8 \%$ were employees, $13.8 \%$ were freelancers, $41.2 \%$ were unemployed, $3.7 \%$ were police officers, $4.3 \%$ were retired $7.4 \%$ were students, $11.8 \%$ were professionals.

In regard to the qualitative variables such as age; the minimum age was 6years. The maximum age was 88years. The first quartile was 46.03years. The median age was 45 years. While third quartile was 75 years. The results breakdowns were as presented in Table 1.

Results of clinical characteristics showed that 88.9 $\%$ of patients with hemodialysis were normal and 11.1 $\%$ were sporadic patients with hemodialysis, $27.4 \%$ were diabetic mellitus and $72.6 \%$ were not diabetic mellitus. $29.5 \%$ had hypertension and $70.5 \%$ had no hypertension. $89.8 \%$ had both diabetes mellitus and hypertension, and $10.2 \%$ had neither diabetes mellitus nor hypertension. $3.4 \%$ had shrunken kidneys and $96.6 \%$ had no shrunken kidneys. Dialysis frequency per week found that two times $(8.8 \%)$ and three times (81.2\%) had polycystic kidney disease and $94.8 \%$ had no polycystic kidney disease. $8.0 \%$ had renal obstruction and $92.0 \%$ had no renal obstruction. $9.5 \%$ were uncertain and $90.5 \%$ were uncertain. $5.8 \%$ had each other, and $94.2 \%$ had no other.

Based on the log rank test, the variables considered to be important in Table 1 and Table 2 with p-value > 0.05 were entered in the mean parametric model, while other variables were not significantly excluded from the parametric model. The variables used in the parametric model were normal, dialysis frequency per week, hospitals, diabetes mellitus, hypertension, diabetes mellitus and hypertension, shrunken kidneys, other.

The median overall survival time was estimated at 84 months and the trust level was found at 95\% (61-89) as shown in Figure 1, which clarified the overall survival curve of hemodialysis patients.

For univariate analysis, an additive Weibull and compertz model are found with similar meaningful 


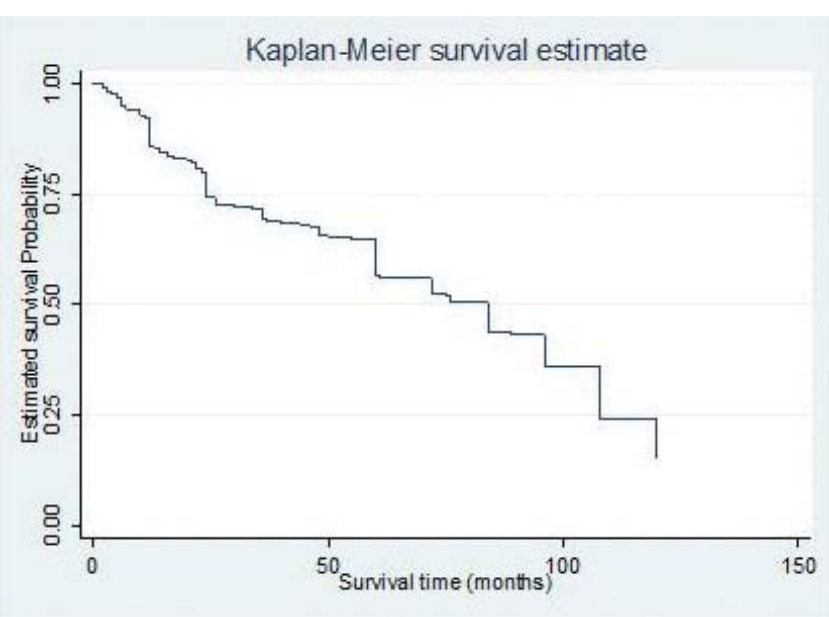

Figure 1. Kaplan-Meier to estimate survival function for hemodialysis patients.

findings for all Wald test variables ( $\mathrm{P}$-value < 0.05). Based on hazard ratio factors; age, diabetes mellitus, diabetes mellitus + hypertension, increased risk of death and other variables were observed; regular, hospital, hypertension, kidney shrunk dialysis frequency per week, and other, respectively, variables were found to have substantially higher survival rates. (see Table 3, 4 , and 5).

Based on a multivariate analysis, it was assessed that risk factors, including age, hospital, dialysis frequen- cy per week, daily dialysis, were significant relative to other variables for the Wald test $(\mathrm{P}$-value $<0.05)$. The most important factors in hemodialysis patients were HR variables, including age (1.014), diabetes mellitus (1.127), diabetes mellitus + hypertension (1.165). On the other side, other factors, such as regular (0.581) hospital, have been noted (see Table 3, 4, and 5).

Table (6) displays AIC, BIC and $R^{2}$ for different models: Exponential, Weibull and Gompertz. Gompertz has the lowest AIC (662.21), BIC (703.83), and the highest $R^{2}(0.211)$.

The variables that match the univariate parametric model are shown in Table 7 . We also found that the Gompertz model is the safest one to use in the future for forecasting. It is selected as it has the lowest AIC and $\mathrm{BIC}$ value.

For these three models, Figures 2, 3 and 4 displays the Cox-Snell residuals, the cumulative hazard function of Cox-Snell residuals (vertical axis) against the Cox-Snell residuals (horizontal axis) calculated below in Map. The fitness of the survival model is more fitting for the short deviation of residuals from the straight line through the origin with a slope of 1 . Then, based on criteria (AIC, BIC) and residual Cox-Snell, the Gompertz model is the better model compared to another parametric model.

Table 1. Demographic characteristics

\begin{tabular}{|c|c|c|c|c|c|}
\hline \multirow{2}{*}{ Variable } & \multirow{2}{*}{ Categories } & \multirow{2}{*}{$\begin{array}{c}\text { Frequency } \\
\mathrm{N}=325\end{array}$} & \multirow{2}{*}{ Percentage \% } & \multicolumn{2}{|c|}{ Log-rank test } \\
\hline & & & & Chi-square test & P-value \\
\hline \multirow[t]{2}{*}{ Sex } & male & 194 & $59.70 \%$ & \multirow[b]{2}{*}{0.66} & \multirow[b]{2}{*}{0.416} \\
\hline & female & 131 & $40.30 \%$ & & \\
\hline \multirow[t]{4}{*}{ Marital status } & divorced & 8 & $2.50 \%$ & \multirow[b]{4}{*}{4.92} & \multirow[b]{4}{*}{0.1778} \\
\hline & married & 232 & $71.40 \%$ & & \\
\hline & single & 78 & $24 \%$ & & \\
\hline & widowed & 7 & $2.20 \%$ & & \\
\hline \multirow[t]{5}{*}{ Education status } & illiterate & 25 & $7.70 \%$ & \multirow[b]{5}{*}{0.5} & \multirow[b]{5}{*}{0.9732} \\
\hline & basic & 106 & $32.60 \%$ & & \\
\hline & intermediate & 15 & $4.60 \%$ & & \\
\hline & secondary & 127 & $39.10 \%$ & & \\
\hline & graduates & 52 & $16 \%$ & & \\
\hline \multirow[t]{7}{*}{ Occupation } & employee & 61 & $18.80 \%$ & \multirow[b]{7}{*}{7.3} & \multirow[b]{7}{*}{0.294} \\
\hline & freelancers & 45 & $13.80 \%$ & & \\
\hline & unemployed & 134 & $41.20 \%$ & & \\
\hline & policemen & 11 & $3.70 \%$ & & \\
\hline & retired & 14 & $4.30 \%$ & & \\
\hline & student & 24 & $7.40 \%$ & & \\
\hline & worker & 36 & $11.1 .8 \%$ & & \\
\hline \multirow[t]{2}{*}{ Age } & minimum & maximum & first quartile & median & third quartile \\
\hline & 6 & 88 & 46.03 & 45 & 75 \\
\hline
\end{tabular}


Reem Yousif MEKKI et al.

Table 2. Clinical characteristics

\begin{tabular}{|c|c|c|c|c|c|}
\hline \multirow[b]{2}{*}{ Variable } & \multirow[b]{2}{*}{ Categories } & \multirow[b]{2}{*}{ Frequency $\mathrm{N}=325$} & \multirow[b]{2}{*}{ Percentage\% } & \multicolumn{2}{|c|}{ Log-rank test } \\
\hline & & & & Chi-square test & P-value \\
\hline \multirow[b]{2}{*}{ daily dialysis } & irregular & 36 & $11.10 \%$ & \multirow[b]{2}{*}{5.35} & \multirow[b]{2}{*}{0.000} \\
\hline & regular & 289 & $88.90 \%$ & & \\
\hline \multirow[b]{6}{*}{ Hospital } & AhemdGasim & 50 & $15.40 \%$ & \multirow[b]{6}{*}{88.57} & \multirow[b]{6}{*}{0.000} \\
\hline & Bhari & 70 & $21.50 \%$ & & \\
\hline & EbnSena & 74 & $22.80 \%$ & & \\
\hline & Omdurman & 62 & $19.10 \%$ & & \\
\hline & Ribat & 25 & $7.70 \%$ & & \\
\hline & Salma Center & 44 & $13.50 \%$ & & \\
\hline \multicolumn{6}{|c|}{ Causes of end stage renal failure among study population } \\
\hline \multirow[b]{2}{*}{ DIABETES MELLITUS } & No & 236 & $72.60 \%$ & \multirow[b]{2}{*}{7.21} & \multirow[b]{2}{*}{0.007} \\
\hline & Yes & 89 & $27.40 \%$ & & \\
\hline \multirow[b]{2}{*}{ HYPERTENSION } & No & 229 & $70.50 \%$ & \multirow[b]{2}{*}{20.31} & \multirow[b]{2}{*}{0.000} \\
\hline & Yes & 96 & $29.50 \%$ & & \\
\hline \multirow{2}{*}{$\begin{array}{l}\text { DIABETES MELLITUS AND } \\
\text { HYPERTENSION }\end{array}$} & No & 292 & $89.80 \%$ & \multirow[b]{2}{*}{4.7} & \multirow[b]{2}{*}{0.0302} \\
\hline & Yes & 33 & $10.20 \%$ & & \\
\hline \multirow[b]{2}{*}{ SHRUNKEN KIDNEYS } & No & 314 & $96.60 \%$ & \multirow[b]{2}{*}{6.39} & \multirow[b]{2}{*}{0.0115} \\
\hline & Yes & 11 & $3.40 \%$ & & \\
\hline \multirow[b]{2}{*}{ DIALYSIS FREQUENCY PER WEEK } & Two times & 61 & $18.80 \%$ & \multirow[b]{2}{*}{21.65} & \multirow[b]{2}{*}{0.000} \\
\hline & three times & 264 & $81.20 \%$ & & \\
\hline \multirow[b]{2}{*}{ POLYCYSTIC KIDNEY DISEASE } & No & 308 & $94.80 \%$ & \multirow[b]{2}{*}{0.05} & \multirow[b]{2}{*}{0.8305} \\
\hline & Yes & 17 & $5.20 \%$ & & \\
\hline \multirow[b]{2}{*}{ RENAL OBSTRUCTIONS } & No & 299 & $92.00 \%$ & \multirow[b]{2}{*}{0.13} & \\
\hline & Yes & 26 & $8.00 \%$ & & 0.7167 \\
\hline & No & 294 & $90.50 \%$ & & \\
\hline UNCERTAIN & Yes & 31 & $9.50 \%$ & 1.25 & 0.2634 \\
\hline & No & 306 & $94.20 \%$ & & \\
\hline OTHER & Yes & 19 & $5.80 \%$ & 7.63 & 0.0058 \\
\hline
\end{tabular}

Table 3. Analysis results for hemodialysis patients using an exponential parametric model in univariate and multivariate analysis

\begin{tabular}{|l|c|c|c|c|c|c|}
\hline Variable & \multicolumn{3}{|c|}{ Univariate } & \multicolumn{3}{c|}{ Multivariate } \\
\hline & Coef $(\hat{\beta})$ & HR $[\exp (\hat{\beta})$ & p-value & Coef $(\hat{\beta})$ & HR $[\exp (\hat{\beta})$ & p-value \\
\hline Age & 0.021 & 1.021 & 0.000 & 0.014 & 1.014 & 0.012 \\
\hline Daily dialysis & -0.987 & 0.373 & 0.000 & -0.543 & 0.581 & 0.017 \\
\hline Hospital & -0.225 & 0.798 & 0.000 & -0.162 & 0.850 & 0.004 \\
\hline Diabetes mellitus & 0.41 & 1.507 & 0.010 & 0.120 & 1.127 & 0.564 \\
\hline Hypertension & -0.423 & 0.655 & 0.024 & -0.414 & 0.661 & 0.076 \\
\hline Diabetes mellitus +hypertension & 0.833 & 2.300 & 0.000 & 0.153 & 1.165 & 0.578 \\
\hline Shrunken kidneys & -2.061 & 0.127 & 0.04 & -1.804 & 0.165 & 0.075 \\
\hline Dialysis frequency per week & -0.408 & 0.665 & 0.024 & -0.409 & 0.664 & 0.018 \\
\hline Other & -1.076 & 0.341 & 0.018 & -0.849 & 0.428 & 0.075 \\
\hline Intercept & & & -2.419 & & 0.001 \\
\hline Coef; coefficient, HR; Hazard Ratio, $p=$ value significant at $<0.05$ level of significance & & &
\end{tabular}


Parametric Survival Models of Hemodialysis Patients in Relation with Patient-Related Factors

Table 4. Analysis results for hemodialysis patients using a Weibull parametric model in univariate and multivariate analysis

\begin{tabular}{|c|c|c|c|c|c|c|}
\hline \multirow[t]{2}{*}{ Variable } & \multicolumn{3}{|c|}{ Univariate } & \multicolumn{3}{|c|}{ Multivariate } \\
\hline & Coef $(\hat{\beta})$ & $\mathrm{HR}[\exp (\hat{\beta})$ & p-value & Coef $(\hat{\beta})$ & $\mathrm{HR}[\exp (\hat{\beta})$ & p-value \\
\hline Age & 0.021 & 1.021 & 0.000 & 0.014 & 1.014 & 0.012 \\
\hline Daily dialysis & -1.046 & 0.351 & 0.000 & -0.562 & 0.570 & 0.014 \\
\hline Hospital & -0.242 & 0.785 & 0.000 & -0.179 & 0.836 & 0.001 \\
\hline Diabetes mellitus & 0.415 & 1.514 & 0.009 & 0.121 & 1.129 & 0.562 \\
\hline Hypertension & -0.418 & 0.658 & 0.026 & -0.426 & 0.653 & 0.069 \\
\hline Diabetes mellitus +hypertension & 0.878 & 2.406 & 0.000 & 0.133 & 1.142 & 0.632 \\
\hline Shrunken kidneys & -2.077 & 0.125 & 0.038 & -1.830 & 0.160 & 0.071 \\
\hline Dialysis frequency per week & -0.736 & 0.479 & 0.000 & -0.388 & 0.678 & 0.026 \\
\hline Other & -1.115 & 0.328 & 0.014 & -0.876 & 0.417 & 0.066 \\
\hline Intercept & & & & -3.438 & & 0.000 \\
\hline Shape parameter & & & & 1.24950 & & \\
\hline
\end{tabular}

Table 5. Analysis results for hemodialysis patients using a Gompertz parametric model in univariate and multivariate analysis

\begin{tabular}{|l|c|c|c|c|c|c|}
\hline Variable & \multicolumn{3}{|c|}{ Univariate } & \multicolumn{3}{c|}{ Multivariate } \\
\hline & Coef $(\hat{\beta})$ & HR $[\exp (\hat{\beta})$ & p-value & Coef $(\hat{\beta})$ & HR $[\exp (\hat{\beta})$ & p-value \\
\hline Age & 0.022 & 1.022 & 0.000 & 0.015 & 1.015 & 0.009 \\
\hline Daily dialysis & -1.032 & 0.356 & 0.000 & -0.514 & 0.598 & 0.025 \\
\hline Hospital & -0.251 & 0.776 & 0.000 & -0.191 & 0.826 & 0.001 \\
\hline Diabetes mellitus & 0.415 & 1.514 & 0.009 & 0.128 & 1.136 & 0.542 \\
\hline Hypertension & -0.406 & 0.666 & 0.031 & -0.411 & 0.663 & 0.079 \\
\hline Diabetes mellitus + hypertension & 0.900 & 2.460 & 0.000 & 0.137 & 1.147 & 0.623 \\
\hline Shrunken kidneys & -2.072 & 0.126 & 0.039 & -1.831 & 0.160 & 0.071 \\
\hline Dialysis frequency per week & -0.726 & 0.484 & 0.000 & -0.359 & 0.698 & 0.040 \\
\hline Other & -1.137 & 0.321 & 0.012 & -0.876 & 0.416 & 0.066 \\
\hline Intercept & & & -3.021 & \\
\hline Shape parameter & & & .011 & 0.000 \\
\hline Coef; coefficient, HR; Hazard Ratio, $\mathrm{p}=$ =value significant at < 0.05 level of significance, other= (Systemic lupus erythematous, tropical disease (malaria), Gout, cardiovascular disease, NSAID). \\
\hline
\end{tabular}

Table 6. Scores of Akaike Information Criterion (AIC) and Baysian Information Criterion (BIC) and R2 for multivariate parametric models

\begin{tabular}{|l|c|c|c|}
\hline Models & Exponential & Weibull & Gompertz \\
\hline AIC & 678.95 & 669.47 & 662.21 \\
\hline BIC & 716.78 & 711.09 & 703.83 \\
\hline$R^{2}$ & 0.198 & 0.209 & 0.211 \\
\hline
\end{tabular}

\section{DISCUSSION}

This research compared various parametric $(\mathrm{PH}) \mathrm{mo}^{-}$ dels to determine the best model for assessing and analyzing the risk factors affecting patients with hemodialysis survival in public hospitals in Khartoum State. In this analysis, we closely tracked the medical history of the targeted patients in the hospitals through the duration before the occurrence of a significant event such as death or living.

In the analysis of survival results, the focus is always on the probability or risk of death at any time after the initial period. One of the reasons for modeling data on survival is to decide which combinations of possible explanatory variables especially affect the type of the hazard function, the care that causes the risk of death 
Table 7. Scores of Akaike Information Criterion (AIC) and Baysian Information Criterion (BIC) forUnivariate Parametric Models

\begin{tabular}{|l|c|c|c|c|c|c|}
\hline Variable & \multicolumn{2}{|c|}{ Exponential } & \multicolumn{2}{c|}{ Weibull } & \multicolumn{2}{c|}{ Gompertz } \\
\hline & AIC & BIC & AIC & AIC & BIC \\
\hline Age & 715.34 & 722.91 & 709.45 & 720.8 & 702.65 & 714 \\
\hline Daily dialysis & 717.67 & 725.27 & 710.66 & 722.01 & 705.01 & 716.37 \\
\hline Hospital & 711.96 & 719.53 & 703.17 & 714.52 & 694.46 & 705.81 \\
\hline Diabetes Mellitus & 728.48 & 736.01 & 723.06 & 734.41 & 717.01 & 728.36 \\
\hline Diabetes Mellitus thypertension & 729.29 & 736.86 & 724.13 & 735.48 & 718.4 & 729.75 \\
\hline Hypertension & 721.78 & 729.35 & 715.26 & 726.61 & 708.58 & 719.93 \\
\hline Shrunken kidneys & 725.46 & 733.03 & 719.96 & 731.31 & 713.98 & 725.33 \\
\hline Dialysis Frequency per week & 716.65 & 724.21 & 711.29 & 722.64 & 705.69 & 717.04 \\
\hline Other & 726.74 & 734.31 & 720.76 & 732.11 & 714.3 & 725.66 \\
\hline
\end{tabular}

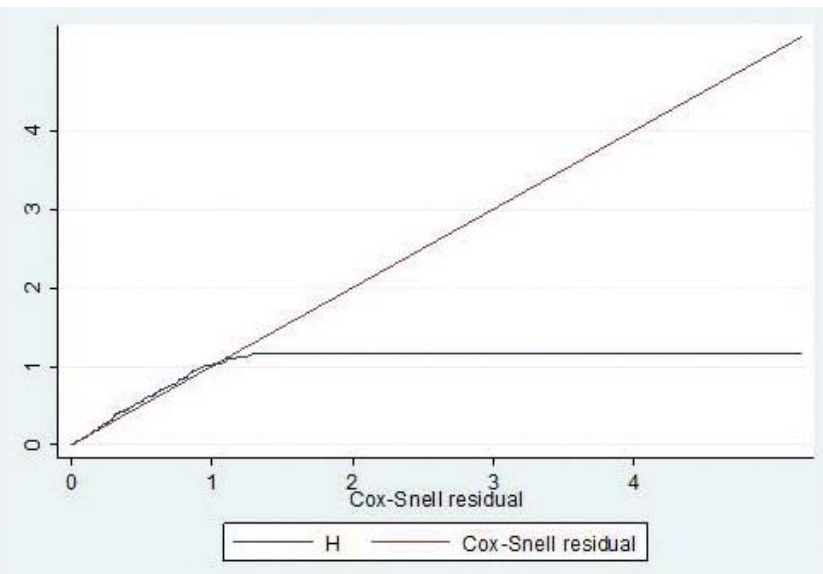

Figure 2. Cox-Snell plot for multivariate Exponential parametric model.

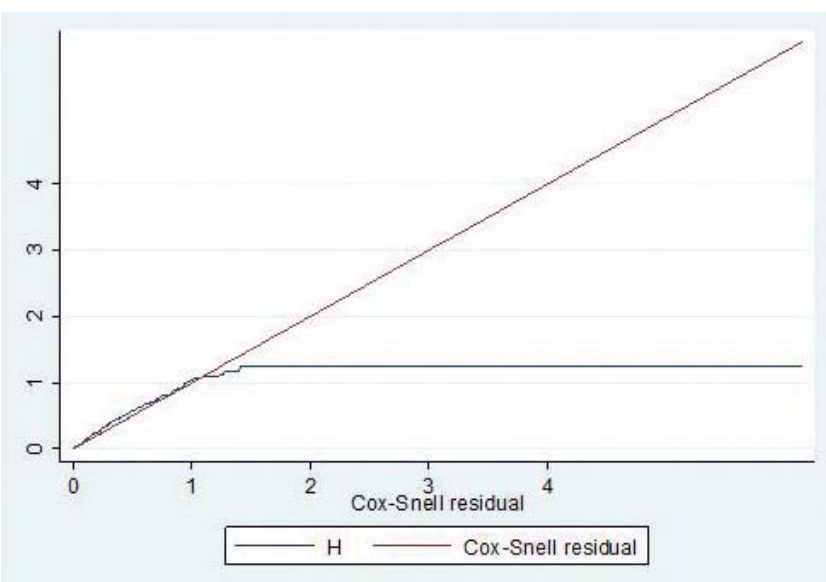

Figure 3. Cox-Snell plot for multivariate Weibull parametric model.

can be measured and the degree to which the hazard feature is impaired by other explanatory variables can be assessed. Another justification for modeling the ha-

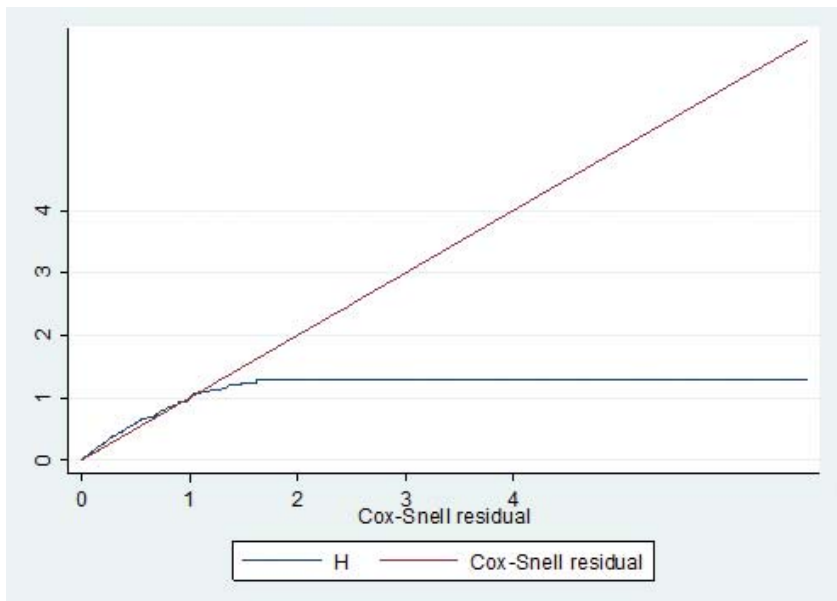

Figure 4. Cox-Snell plot for multivariate Gompertz parametric model.

zard function is for individuals to achieve an approximation of the hazard function itself ${ }^{2}$.

The quantitative variables were not distributed as usual in this research, as indicated in the data analysis, so the parametric models were used. In the log-rank test, the variables were important and were incorporated into parametric models. To estimate variables, univariate and multivariate tests were used.

The univariate analysis study for three models (Exponential, Weibull, and Gompertz) showed that all variables were important effects. We also found that age, diabetes mellitus, both diabetes mellitus and hypertension, increased the risk of death in patients (shorter survival) so that they could influence survival in the univariate model of this study. Other variables (regular, hospital, hypertension, shrunk kidneys, dialysis frequency per week, others) have decreased the risk of death (longer survival) and have a direct effect on the 
survival of the hemodialysis patient.

Multivariate analysis showed that many variables were insignificance. From the results based on Criteria (AIC, BIC) and the highest $R^{2}$. Multivariate analysis found that many variables were negligible. From the results based on Parameters (AIC, BIC) and the highest $R^{2}$ in addition to Cox-Snell residual, we have found that Gompertz is the best model. It is therefore the most efficient fit model among other parametric models for patient hemodialysis data in addition to Cox-Snell residual; we found that the Gompertz is the best model.

Similar findings were found in previous studies ${ }^{20}$, indicating that age, and diabetes mellitus were important variables and hypertension, and the frequency of dialysis per week was negligible. Reference to (Exponential, Weibull and Gompertz) univariate and multivariate statistical analysis in hemodialysis patients showed that Weibull was chosen as the most effective model. The univariate findings were important in this analysis, but they were negligible in the multivariate. In another study conducted by 21 , era, diabetes mellitus, hypertension, were negligible except for clinical significance. It was shown that the Weibull model was the best fit among the parametric models of hemodialysis patients. In this analysis, only the clinic and hospital variable was important in the Exponential model.

In view of the Gompertz multivariate model, which was a major value of the Wald test for various variables, like daily dialysis $\left(\beta-\mathrm{pop}=-0.514, \mathrm{HR}=\mathrm{e}^{\wedge} \beta-\right.$ pop $=0.598, \mathrm{P}=0.025)$ hospital $(\beta-\mathrm{pop}=-0.191, \mathrm{HR}=$ $\mathrm{e}^{\wedge} \beta$-pop $\left.=0.826, \mathrm{P}=.001\right)$, age $\left(\beta-\mathrm{pop}=0.015, \mathrm{HR}=\mathrm{e}^{\wedge} \beta-\right.$ $\mathrm{pop}=1.015, \mathrm{P}=0.009)$, dialysis Frequency per week $(\beta-$ pop $=-0.359, H R=e^{\wedge} \beta$-pop=0.698, $\left.\mathrm{P}=0.040\right)$, when the $(\mathrm{P}<0.05)$ was achieved. That said, the approximate coefficient and risk ratio were also important and had a clear impact on the survival of hemodialysis patients in this study.

In the light of the above study, the model centered on these variables was important among the other models that were excluded from this research. These va- riables (daily dialysis, hospital, age, dialysis Frequency per week) must therefore be included in the model. The final multivariate Gompertz PH model was then defined.

$\mathrm{h}(\mathrm{t} \mid \mathrm{x})=0.049 \exp (0.011 \mathrm{t}) \exp (-0.514$ daily dialysis -0.191 hospital +0.015 age -0.359 dialysis Frequency per week)

According to $\mathrm{HR}$, the variables including age, diabetes mellitus, diabetes mellitus +hypertension, were considered to be highly significant factors in hemodialysis patients in the three models used in the research in particular multivariate analysis. Whereas other factors, such as regular in dialysis, hypertension, shrunken kidneys, dialysis frequency per week, and other, had substantially lower survival rates.

This research has its drawbacks, that is, the incompleteness of the majority of patient records and the lack of data that make it difficult to determine the real cause of the outbreak of the disease in Sudan. It is due to the fact that certain variables were not included in this analysis because they were not included in the patient medical record.

\section{CONCLUSION}

Gompertz distribution model is being the best for hemodialysis patient's analysis. Some variables such as (age, daily dialysis, hospital, dialysis frequency per week) were significant factors. The study clarified that some variables like regular in dialysis were significant factor.

Compliance with ethics requirements: The authors declare no conflict of interest regarding this article. The authors declare that all the procedures and experiments of this study respect the ethical standards in the Helsinki Declaration of 1975, as revised in 2008(5), as well as the national law. Informed consent was obtained from all the patients included in the study. 


\section{References}

1. Kleinbaum, David G, and Mitchel Klein (2012). Survival AnalysisA Self-Learning Tex. Third Edition. New York: Springer Science + Business Media.

2. Collett, David. (2003). Modelling Survival Data in Medical Research. Second Edition. London: Chapman \& Hall.

3. Lee, Elisa T, and John Wenyu Wang.(2003). "Some Well-Known Parametric Survival Distributions and Their Applications", Statistical Methods for Survival Data Analysis. Third Edition.Canada. John Wiley \& Sons, Inc., Hoboken, New Jersey.

4. Pagee, Jama Patient (2007). Chronic Kidney Disease. jama.jamanetwork.com (Accessed 6 28, 2012).

5. Elamin, Abdelsamee E. M., Nagah A. A. Mohammed, and Gad Allah Modawe (2012). Aetiology of End-Stage Renal Disease among Adult Sudanese Patients.Sudan medical journal,7(4):255-258

6. Banaga, A. S., Mohammed, E. B., Siddig, R. M., Salama, D. E., Elbashir, S. B., Khojali, M. O., et al (2015). Causes of end stage renal failure among haemodialysis patients in Khartoum State/ Sudan. BMC Res Notes, 8:502.

7. Altman, DG, BL De Stavola, SB Love, and KA Stepniewska. (1995). Review of survival analyses published in cancer journals. British Journal of Cancer,72: 511-518.

8. George, Brandon, Samantha Seals, and Inmaculada Aban (2014). Survival analysis and regression models.J Nucl Cardiol,21(4):686-694.

9. Abdelaal, Medhat Mohamed Ahmed, and Sally Hossam Eldin Ahmed Zakria. (2015). Modeling Survival Data by Using Cox Regression Model. American Journal of Theoretical and Applied Statistics,4(6):504-512.

10. Bradburn, M J, T G Clark, S B Love, and D G Altman.(2003).urvival analysis. Part II: Multivariate data analysis - an introduction to concepts and methods. Birtish Journal of Cancer, 89(3):431436
11. Lawless, Jerald F. (2003). Statistical Models and Methods for Lifetime Data. Second Edition. New York: John Wiley \& Sons.

12. Pourhoseingholi, Mohamad Amin, Ebrahim Hajizadeh, Bijan Moghimi Dehkordi, Azadeh Safaee, Alireza Abadi, and Mohammad Reza Zali.(2007).Comparing Cox Regression and Parametric Models for Survival of Patients with Gastric Carcinoma Asian Pacific J Cancer Prev,8: 412-416.

13. Akaike, H. (1974). A new look at the statistical model identification.IEEE Trans Automatic Control,19(6):716-723.

14. Klein, John P, and Melvin L Moeschberger.(1997).Survival Analysis: Techniques for Censored and Truncated Data .New York: Springer-verlag.

15. Saikia, Rinku, and Manash Pratim Barman. (2017).A Review on Accelerated Failure Time Models. International Journal of Statistics and Systems, 12: 311-322

16. Schwarz, Gideon E. (1978). Estimating the Dimension of a Model.The Annals of Statistics,6: 461-46

17. Hosmer JR, David W, Stanley Lemeshow, and Susanne May. (2011).Applied survival analysis: regression modeling of time to event data. Hoboken, New Jersey: John Wiley \& Sons,

18. Stevenson, Mark. December (2007).An Introduction to Survival Analysis. EpiCentre.massey.ac.nz.

19. Cox, D.R, and E.J Snell. E.(1968).A General Definition of Residuals (with discussion). Journal of the Royal Statistical Society, 30: 248-275.

20. Vahedi, Mohsen, Mahmood Mahmoodi, Kazem Mohammad,et al.:(2016). What is the Best Parametric Survival Models for Analyzing Hemodialysis Data. Global Journal of Health Science., 8(10):118-126.

21. Montaseri, Maryam, Jamshid Yazdani Charati, and Fateme Espahbodi (2016). Application of Parametric Models to a Survival Analysis of Hemodialysis Patients. Nephrourol Mon,8(6) e28738. 